\title{
Effect of cryopreservation on the cellular integrity of equine embryos
}

\author{
T Tharasanit, B Colenbrander and T A E Stout \\ Faculty of Veterinary Medicine, Department of Equine Sciences, Utrecht University, Yalelaan 12, 3584 CM, \\ Utrecht, The Netherlands
}

Correspondence should be addressed to T Tharasanit; Email: T.Tharasanit@vet.uu.nl

\begin{abstract}
Horse embryos are rarely cryopreserved in practice because expanded blastocysts tolerate freezing poorly, and the embryo begins expanding very soon after entering the uterine cavity. This study examined the effects of freezing on cytoskeleton integrity, and investigated whether cell damage could be reduced using trypsin to thin the blastocyst capsule or cytochalasin-B (cyto-B) to stabilise the cytoskeleton. Sixty-nine embryos were recovered 7 days after ovulation and equilibrated in $10 \%$ glycerol, with or without pretreatment with $0.2 \%$ trypsin or $7.5 \mu \mathrm{g} / \mathrm{ml}$ cyto-B. Forty-two of the embryos were frozen; the rest were used to determine whether pre-freezing treatment alone caused cell damage. Subsequently, embryos were stained with 4',6-diamidino-2-phenylindole dihydrochloride, to identify dead cells, and fluorescently labelled phalloidin, to assess cytoskeleton quality. Without freezing, none of the treatments affected cell viability. And although Cyto-B altered actin distribution, the cytoskeleton returned to normal during a 4-h culture. Following cryopreservation, the percentage of dead cells $(11.1 \pm 1.3 \%)$ did not differ between treatments $(P>0.05)$, but significantly fewer cells died in small $(\leq 300 \mu \mathrm{m})$ than in large embryos when neither pretreatment was used $(P>0.05)$; the effect of embryo size was, however, not significant after pretreatment with trypsin or cyto-B, and trypsin improved the likelihood of an intact cytoskeleton post thaw. However, trypsin treatment also resulted in a 'sticky' capsule that complicated embryo handling, and cyto-B-induced actin-depolymerisation was not reversed during a 6-h post-thaw incubation. Thus, while trypsin pretreatment improved cytoskeleton preservation and both trypsin and cyto-B may reduce cell death during cryopreservation of large embryos, both treatments induced other changes likely to compromise embryo survival.

Reproduction (2005) 129 789-798
\end{abstract}

\section{Introduction}

During the past decade, embryo transfer (ET) has become increasingly widespread within the sport-horse breeding industry; pregnancy rates of $50-80 \%$ are now commonly achieved after non-surgical transfer of embryos either directly after recovery (Vogelsang et al. 1985, Meira et al. 1993, Riera \& McDonough, 1993, McKinnon et al. 1998) or after storage at $5{ }^{\circ} \mathrm{C}$ for up to $24 \mathrm{~h}$ (Carnevale et al. 1987, Carney et al. 1991). However, the commercial exploitation of equine ET has been restricted by the limited success of embryo cryopreservation and the high costs and moderate success of superovulation (Squires et al. 2003); the need to synchronise multiple recipient mares for a mean of only 0.7 embryos per flush increases the costs dramatically (Palmer \& Jousset 1975, Squires et al. 1999).

Acceptable pregnancy rates can be achieved with frozen-thawed horse embryos (50-60\%: Skidmore et al. 1991, Lascombes \& Pashen 2000) only if the embryos are frozen at an early developmental stage (day 6-6.5; morula to early blastocyst) when they are less than $250 \mu \mathrm{m}$ in diameter (Slade et al. 1985), i.e. shortly after their arrival in the uterus at around day 6 after ovulation (Battut et al. 1997). Unfortunately, the precise time of uterine entry and rate of embryo development differ depending on the time of year, type of semen used (fresh vs frozen) and mare age (Meadows et al. 1999).

The reason why larger equine blastocysts do not tolerate cryopreservation is not clear, but it has been proposed that it involves the acellular capsule that forms around the embryo during blastulation (Betteridge et al. 1982, Flood et al. 1982). A negative correlation between capsule thickness and freezability has led to the suggestion that the capsule may impede access of cryoprotectants to the embryo proper (Legrand et al. 1999, Bruyas et al. 2000). Indeed, partially digesting the capsule by immersing expanded blastocysts in a trypsin solution prior to freezing resulted in an unusually high pregnancy rate after subsequent thawing and transfer to recipient mares in one 
report (6/8: Legrand et al. 2000), but not others (3/11: Legrand et al. 2002, 0/14: Maclellan et al. 2002). The probable cause of reduced embryo viability during freezing and thawing is the disruption of cell organelles, in particular the cytoskeleton, as a result of intracellular ice formation (Wilson et al. 1987, Dobrinsky 1996). Cytochalasin B (cyto-B) is a reversible inhibitor of actin polymerisation which, by temporarily deconstructing the actin filaments, has been shown to reduce cytoskeleton damage during cryopreservation and, thereby, improve the viability of frozen-thawed porcine embryos (Dobrinsky et al. 2000). Maclellan et al. (2002) reported that expanded horse blastocysts treated with cyto-B prior to cryopreservation subsequently yielded pregnancies (3/7) at a similar rate to embryos frozen using a conventional glycerol protocol (4/7), and contained similar levels of dead cells; they did not examine the effect of cyto-B on embryonic cytoarchitecture. Moreover, while the effects of cryopreserving equine embryos on the microstructure of some cellular organelles (e.g. mitochondria; Wilson et al. 1987, Bruyas et al. 1993, Ferreira et al. 1997) has been examined, the conclusions with regard to the degree of damage and proportion attributable to cryoprotectant are conflicting, and the effect on the cytoskeleton has not been reported. The aims of the current study were to investigate the level of cytoskeleton disruption suffered by horse embryos during freezing and thawing using glycerol as cryoprotectant, and to examine whether additional prefreezing treatment with trypsin to thin the capsule or cytoB to temporarily depolymerise the cytoskeleton would improve post-thaw cell viability and actin cytoskeleton integrity.

\section{Materials and Methods}

\section{Embryo production, collection and pre-freezing examination}

Sixty-nine embryos were recovered from Dutch Warmblood mares 7 days after an ovulation was detected during daily ultrasonographic examination of the ovaries; embryos were thus $7.5 \pm 0.5$ days old at recovery. During the preceding oestrus and beginning when the dominant follicle(s) exceeded $35 \mathrm{~mm}$ in diameter, mares had been inseminated every second day with $300-500 \times 10^{6}$ progressively motile sperm from a stallion of proven fertility. Embryos were collected by non-surgical uterine lavage using 3L Dulbecco's phosphate-buffered saline (PBS) supplemented with $0.5 \%$ $(\mathrm{v} / \mathrm{v})$ heat-inactivated fetal bovine serum (Sigma-Aldrich Chemicals BV, Zwijndrecht, The Netherlands). Immediately after recovery, the embryos were examined using a stereoscopic dissecting microscope and assigned a quality score of $1-5 \quad(1=$ excellent, $5=$ degenerate or dead; McKinnon \& Squires 1988). Only grade 1 and 2 embryos (excellent and good) were used in this experiment, and these were washed and then transported to the laboratory at room temperature $\left(\sim 25^{\circ} \mathrm{C}\right)$ in ovum culture medium (OCM; ICN Biomedicals, Zoetermeer, The Netherlands).
Upon arrival at the laboratory and within $1 \mathrm{~h}$ of collection, the diameter of each embryo, excluding its zona pellucida and/or capsule, was measured using a microscope equipped with an eyepiece micrometer. Next, the embryos were washed using PBS ( $\mathrm{pH} 7.2$; Gibco BRL, Paisley, Strathclyde, UK) and stained with $0.1 \mu \mathrm{g} / \mathrm{ml}$ of the nontoxic, fluorescent membrane-impermeable DNA stain 4',6diamidino-2-phenylindole dihydrochloride (DAPI; Molecular Probes Europe BV, Leiden, The Netherlands) in PBS at $37^{\circ} \mathrm{C}$ to identify any dead cells, as described by Huhtinen et al. (1995). Labelled embryos were examined using a conventional fluorescent microscope (BH2-RFCA; Olympus, Tokyo, Japan) equipped with a digital camera (Coolpix990; Nikon Instruments Europe B.V., Badoevedorp, The Netherlands); images were recorded after exposing the embryos to u.v. light for approximately $30 \mathrm{~s}$.

\section{Experiment I: The effect of pre-freezing treatments on cellular and cytoskeletal integrity}

Seventeen embryos were used to study the effect on cell viability and actin cytoskeleton quality of treatment with cryoprotectant (glycerol) alone or in combination with trypsin or cyto-B, without subsequent freezing and thawing. Four embryos were subjected to a standard pre-freezing, four-step, $10 \%$ glycerol equilibration procedure, i.e. 10 min each in 2.5, 5, 7.5 and $10 \%$ glycerol in PBS at room temperature $\left(25^{\circ} \mathrm{C}\right)$. A further five embryos were immersed in $0.2 \%(\mathrm{w} / \mathrm{v})$ trypsin in PBS (Sigma-Aldrich Chemicals BV) for $15 \mathrm{~min}$ at $37^{\circ} \mathrm{C}$ (as described by Legrand et al. 2000) before equilibration in the glycerol solutions, and the remaining eight embryos were equilibrated in glycerol solutions containing $7.5 \mu \mathrm{g} / \mathrm{ml}$ cyto-B (dissolved in dimethylsulphoxide; both Sigma-Aldrich Chemicals BV). After the 10-min incubation in 10\% glycerol, the cryoprotectant and cyto-B were washed out using a reversed four-step equilibration in PBS containing decreasing glycerol concentrations (10 min each at 7.5, 5, 2.5 and $0 \%$ ). After the final wash, the embryos were restained with DAPI so that dead cells could again be counted. Thereafter, embryos were fixed overnight in $4 \%$ paraformaldehyde and stored in PBS at $4{ }^{\circ} \mathrm{C}$ until further analysis. Of the eight cyto-B-treated embryos, two were stained and fixed immediately after removal of the cryoprotectant while the remaining six were first incubated in $\mathrm{OCM}$ at $37^{\circ} \mathrm{C}$ for either $2 \mathrm{~h}(n=2)$ or $4 \mathrm{~h}(n=4)$. An additional ten embryos were fixed without either freezing or any other treatment, to establish 'normal' percentages of dead cells and patterns of actin distribution.

\section{Experiment II: Effect of cryopreservation on cell viability and cytoarchitecture}

After DAPI staining to count the number of dead cells, 42 embryos were assigned randomly to one of the three freezing protocols outlined above: 14 embryos using the glycerol-alone protocol, 11 after pretreatment with trypsin and 17 in glycerol solutions containing cyto-B. Six of the 
cyto-B embryos were assigned to a further 6-h culture post thaw to examine whether the effects of cyto-B on the actin cytoskeleton could be reversed after freezing and thawing. The ten untreated, unfrozen embryos described in experiment I were again used as the control group.

\section{Freezing and thawing protocols}

Cryopreservation was performed essentially as described by Czlonkowska et al. (1985). Briefly, the equilibrated embryo was loaded into a $0.25 \mathrm{ml}$ polyvinyl chloride straw (IMV Technologies, L'Aigle, France) in a droplet of $10 \%$ glycerol solution sandwiched between two air bubbles. The straw was sealed with a straw plug and placed vertically in a programmable controlled-rate freezing machine (Planer Kryo 10 Series II, Sunbury-onThames, UK). Initial cooling was at $1{ }^{\circ} \mathrm{C} / \mathrm{min}$ from ambient temperature down to $-6^{\circ} \mathrm{C}$, at which temperature the straws were held for $5 \mathrm{~min}$ and 'seeded' by running metal forceps precooled in liquid nitrogen along them. After seeding, cooling was continued at $0.3{ }^{\circ} \mathrm{C} / \mathrm{min}$ down to $-33^{\circ} \mathrm{C}$, where the straws were held for $10 \mathrm{~min}$ before being plunged into liquid nitrogen. All embryos were stored in liquid nitrogen for at least 1 week before thawing for further examination.

The straws were thawed by holding them in the air for $10 \mathrm{~s}$ and then submerging them in $35^{\circ} \mathrm{C}$ water for $1 \mathrm{~min}$. Next, the embryo was expelled into a PBS solution containing $10 \%$ glycerol and $0.25 \mathrm{M}$ sucrose (Sigma-Aldrich Chemicals BV). The cryoprotectant was then washed out by incubating the embryos for $10 \mathrm{~min}$ each in solutions of $0.25 \mathrm{M}$ sucrose in PBS containing decreasing concentrations of glycerol $(7.5,5,2.5$ and $0 \%)$. Finally, the embryos were restained with DAPI to allow the number of dead cells to be counted, fixed overnight in $4 \%$ paraformaldehyde and stored in PBS at $4{ }^{\circ} \mathrm{C}$ until analysis of total cell number and cytoskeleton quality.

\section{Assessing actin cytoskeleton integrity}

To visualise the actin cytoskeleton, embryos were permeabilised by immersion in $0.1 \%$ Triton X-100 in PBS for $10 \mathrm{~min}$, and then stained for $1 \mathrm{~h}$ at room temperature with a $15 \mu \mathrm{g} / \mathrm{ml}$ solution of Alexa Fluor 488-phalloidin (Molecular Probes Europe BV) in PBS. After washing in PBS, the embryos were counterstained with $0.1 \mu \mathrm{g} / \mathrm{ml}$ DAPI to count cell nuclei. To localise the cell plasma membrane, a number of embryos were labelled for $1.5 \mathrm{~h}$ at room temperature with a $5 \mu \mathrm{g} / \mathrm{ml}$ solution of a wheat germ agglutinin (WGA)-Alexa Fluor 594 conjugate (Molecular Probes Europe BV) in PBS. Labelled embryos were mounted on glass microscope slides with an antifade medium to retard photobleaching (vectashield; Vector Laboratories, Burlingame, CA, USA), sealed under a coverslip using nail polish and stored in the dark at room temperature until they could be analysed using either a Leica TCS SP confocal laser-scanning microscope or a Bio-Rad Radiance 2100MP confocal and multiphoton system (Bio-Rad,
Hemel-Hempstead, UK) mounted on a Nikon TE300 inverted microscope (Uvikon, Bunnik, The Netherlands). A combination of a 488-argon ion and a 543-helium neon laser was used to produce sequential optical scans of the Alexa Fluor 488-phalloidin-labelled actin cytoskeleton and the WGA-Alexa Fluor 594-labelled plasma membrane respectively. The DAPI-stained nuclear material was excited using a $100 \mathrm{fs}$ pulsed $780 \mathrm{~nm}$ excitation laser source (a mode-locked titanium:sapphire laser; Tsunami; Spectra Physics, Mountain View, CA, USA). The images produced by sequential scans via the different colour channels were then merged and recorded in digital format. Subsequently, the images were displayed using Adobe Photoshop 7 software (Adobe Systems Inc., Mountain View, CA, USA) and the appearance of the actin cytoskeleton was assessed. Following cytoskeleton assessment, the embryos were flattened by gently pressing on the coverslip and the total number of cells in each embryo was counted, using a conventional fluorescent microscope equipped with an eyepiece counting grid, for calculation of the percentage of dead cells.

\section{Statistical analysis}

The percentage of cells that died during freezing and thawing was calculated as the increase in the number of DAPI-positive cells divided by the total cell number. Prefreezing embryo diameter and the extent of freezinginduced cell death were compared between experimental groups using one-way ANOVAs with a Bonferroni correction. Non-parametric tests (Kruskal-Wallis and MannWhitney $U$ ) were used to compare post-thaw actin cytoskeleton quality. In all cases, the statistics were performed using SPSS 11.0 for Windows (SPSS Inc., Chicago, IL, USA), and differences were considered significant when $P<0.05$.

\section{Results}

\section{Actin cytoskeleton quality in horse embryos}

Horse embryos fixed and stained immediately after collection were typified by intense actin staining precisely and evenly organized within the cell cortex, such that the cell borders were sharply demarcated; this pattern was used as a standard for 'good' actin cytoskeleton morphology (grade I: Fig. 1A). The appearance of the actin cytoskeleton changed when embryos were treated with cyto-B or frozen and thawed, and the extent of this cytoskeleton disruption was accounted for by the creation of a further two quality grades. A grade II actin cytoskeleton was characterised by large areas where the cell borders, although grossly maintained, were indistinct and stained only patchily, and where small clumps of actin were visible within the cytoplasm (Fig. 1B). A grade III cytoskeleton had large areas where the cell borders lacked obvious actin staining and where, instead, most of the visible actin was in the form of intracytoplasmic clumps (Fig. 1C). 

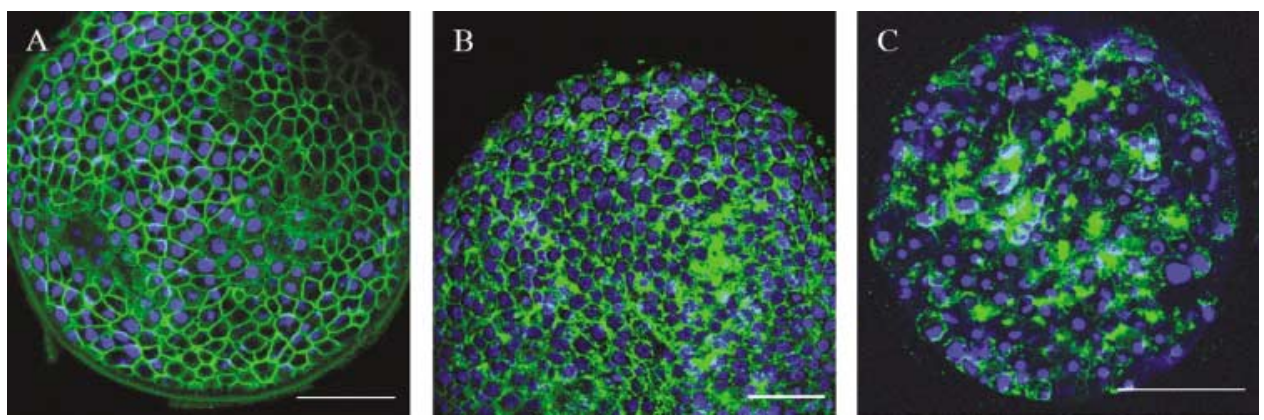

Figure 1 Photomicrographs to illustrate the actin cytoskeleton quality scoring system (grades I-III) developed for horse embryos examined using a multiphoton laser-scanning microscope. The embryos were stained with Alexa Fluor 488-phalloidin (green) to visualise actin filaments and DAPI to stain the cell nuclei (blue). (A) A grade I cytoskeleton was typified by precise, sharp restriction of actin staining to the cell borders. (B) Grade II was characterised by a less distinct outlining of the cells combined with occasional small clumps of actin in the cytoplasm and (C) a grade III actin cytoskeleton had large areas lacking actin staining, with the visible actin largely agglomerated in intracytoplasmic clumps. Scale bars represent $100 \mu \mathrm{m}(\mathrm{A}$ and $\mathrm{B})$ and $50 \mu \mathrm{m}(\mathrm{C})$.

\section{Experiment I}

The 17 embryos used to examine the effect of pre-freezing treatment (glycerol \pm trypsin or cyto-B) on cell viability and cytoskeleton structure contained a mean \pm S.E.M. of $1948 \pm 612$ cells. The mean percentage of cells dead at embryo recovery was $0.1 \pm 0.0 \%$, and this figure was not increased by any of the pre-freezing treatments (Table 1). All of the embryos that had been exposed to glycerol alone or trypsin followed by glycerol were recorded to have a grade I actin cytoskeleton following washing to remove the glycerol (Figs 2 and 3A and B). By contrast, the actin cytoskeleton changed dramatically in embryos incubated in glycerol solutions containing $7.5 \mu \mathrm{g} / \mathrm{ml}$ cyto-B. In general, cyto-B treatment resulted in a lower intensity of actin labelling at the cell cortex and the appearance of patches of actin staining within the cytoplasm (i.e. a grade II cytoskeleton; Fig. 3C). With regard to the reversibility of the cyto-B effect, the actin cytoskeleton did not repolymerise during a subsequent 2-h incubation in cyto-B-free culture medium (Fig. 3D), but incubation for $4 \mathrm{~h}$ was sufficient to allow recovery of a 'normal' grade I actin cytoskeleton pattern (Figs 2 and 3E).

\section{Experiment II}

Mean \pm S.E.M. embryo diameter $(382 \pm 25.6 \mu \mathrm{m}$; range $160-1000 \mu \mathrm{m})$, total cell number $(1591 \pm 226)$ and percentage of dead cells $(0.1 \pm 0.0)$ prior to freezing did not differ between the experimental groups. However, the number of embryos that fractured during thawing did tend to differ between treatments (2/14 conventionally frozen, 3/11 trypsin-treated, 0/17 cyto-B-treated; $P=0.09$ ); only the actin cytoskeleton quality of intact areas of the fractured embryos could subsequently be analysed meaningfully.

The mean percentage of dead cells following freezing and thawing did not differ significantly between the conventional, trypsin- and cyto-B-treated groups (14.6 \pm 2.4 , $9.6 \pm 2.8$ and $9.7 \pm 2.4 \%$ respectively; Table 2 ). However, the percentages of dead cells post thaw were significantly higher than in control, non-frozen embryos (0.15 $\pm 0.6 \% ; P<0.001)$.

With regard to the effect of embryo size on freezability, embryos $>300 \mu \mathrm{m}$ in diameter had a significantly higher percentage of dead cells post thaw than those $\leq 300 \mu \mathrm{m}$ if they were frozen without additional trypsin or cyto-B treatment $(19.0 \pm 2.9$ vs $8.5 \pm 2.1 \% ; P<0.05)$.

On the other hand, the effect of blastocyst size on freezing-induced cell death was not statistically significant if embryos were pretreated with either trypsin $(13.8 \pm 4.9$ vs $5.4 \pm 0.7 \% ; \quad P=0.14) \quad$ or $\quad$ cyto-B $\quad(12.3 \pm 5.5 \quad$ vs $8.1 \pm 2.3 \% ; P=0.32$; Table 2 ), primarily because the percentage of dead cells in larger embryos tended to be lower in these groups. As for the actin cytoskeleton, eight of the ten $(80 \%)$ non-frozen control embryos had a grade I cytoskeleton (Figs 1A and 4), and freezing and thawing led to a dramatic drop in mean cytoskeleton quality. Mean cytoskelton quality also tended to differ between freezing protocols $(P=0.058)$; in particular, the number of embryos that retained a grade 1 cytoskeleton post thaw

Table 1 The average number of cells and percentages that were dead in horse embryos at recovery and after treatment with glycerol \pm trypsin or ctyo-B, without cryopreservation. Values are means \pm S.E.M.

\begin{tabular}{lccc}
\hline & & \multicolumn{2}{c}{ Average \% dead cells } \\
\cline { 3 - 4 } Pre-freezing treatment (number of embryos) & Total cells per embryo & At recovery & After treatment \\
\hline Glycerol (4) & $1948 \pm 612$ & $0.0 \pm 0.0$ & $0.0 \pm 0.0$ \\
Trypsin + glycerol (5) & $1562 \pm 602$ & $0.1 \pm 0.1$ & $0.2 \pm 0.1$ \\
Cyto-B + 0-2 h of culture (4) & $1185 \pm 256.1$ & $0.1 \pm 0.1$ & $0.1 \pm 0.1$ \\
Cyto-B + 4 h of culture (4) & $999 \pm 241$ & $0.0 \pm 0.0$ & $0.0 \pm 0.0$ \\
\hline
\end{tabular}




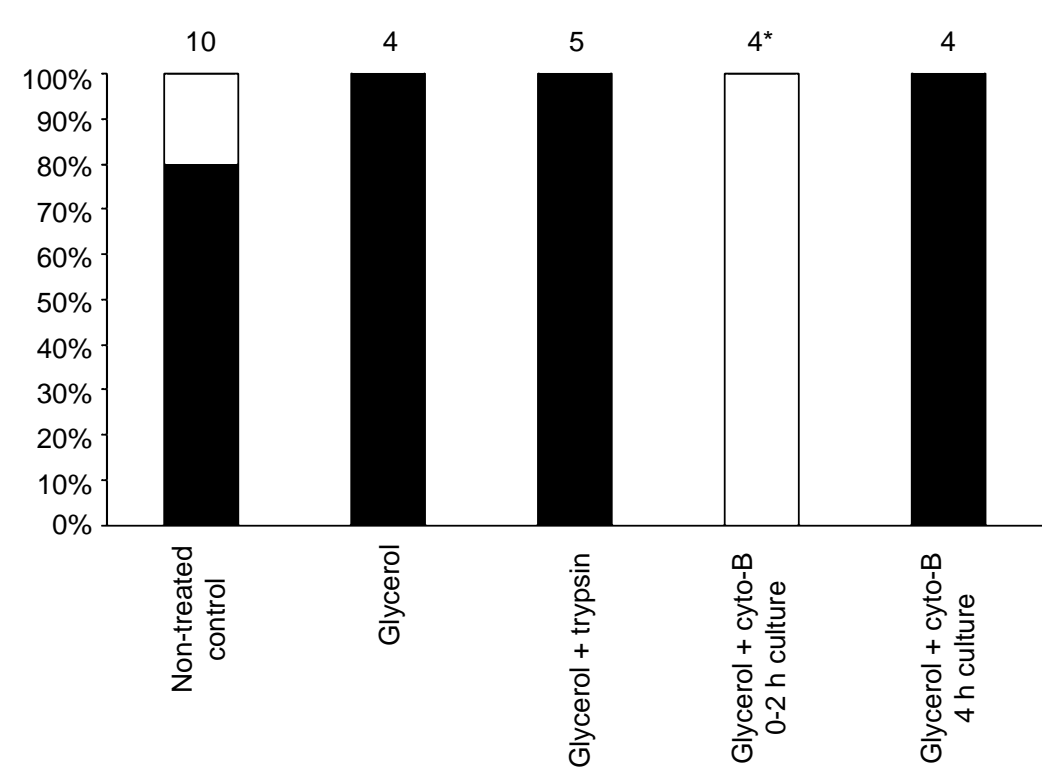

Figure 2 Actin cytoskeleton quality (grades I-III) in horse embryos immediately after collection (controls) or after glycerol, trypsin or cyto-B pretreatment, without cryopreservation. Solid bars = grade I; open bars = grade II. The numbers of embryos in each group is noted above each column. *Cyto-B treatment significantly reduced mean cytoskeleton quality $(P<0.05)$.

was significantly higher in trypsin-treated (4 of 11) than in the conventionally frozen (0 of 14$)$ or cyto-B-treated $(0$ of 17) groups ( $P=0.002$; Fig. 3J). Immediately post thaw, all of the frozen-thawed cyto-B-treated embryos had a grade II actin cytoskeleton pattern (Fig. 3K), similar to that described in experiment I for embryos treated with cyto-B without freezing and thawing. In this case, however, a $6-\mathrm{h}$ post-thaw incubation in cyto-B-free medium was not sufficient to return the actin cytoskeleton to a grade I appearance (Fig. 3L).

The fluorescently labelled lectin, WGA, was used to verify the location of the plasma membrane with respect to the actin cytoskeleton (Fig. $3 \mathrm{~F}-\mathrm{H}$ ) and to determine whether disruption of the latter during cryopreservation necessarily correlated with loss of plasma membrane integrity. The dual staining revealed that actin cytoskeleton disruption, typified by dispersal of actin labelling from the cell borders, often occurred in the absence of any disruption of the adjacent plasma membrane (Fig. 3I).

\section{Discussion}

The success of equine embryo cryopreservation depends critically on embryo size and developmental stage (Slade et al. 1985, Skidmore et al. 1991), but recovering early embryos likely to survive freezing and thawing is labour intensive, and complicated by variations in the rate of embryo development. This problem could be circumvented by treatments to hasten embryonic descent into the uterus (e.g. applying prostaglandin E2 to the oviduct; Robinson et al. 2000) or techniques to successfully cryopreserve expanded blastocysts. With regard to the latter, it would help to first establish the type and extent of damage suffered by expanded blastocysts during cryopreservation, and then to determine which indices of damage correlate with embryo survival after transfer. In the current study, freezing and thawing horse embryos using glycerol as cryoprotectant resulted in disruption of the cytoskeleton and appreciable cell death, particularly in large $(>300 \mu \mathrm{m})$ embryos. The higher rate of cell death in larger embryos (19 vs $8.5 \%$ ) probably explains their reduced viability; previous studies have demonstrated that inner cell mass cells are more susceptible than trophectoderm cells to freezing-induced damage (Wilson et al. 1987, Bruyas et al. 1993, 1995, 2000). As dramatic as the cell death, however, was the freezing-induced disruption of the actin cytoskeleton within an intact cell plasma membrane. Irreversible cytoskeleton disruption would render the affected cell non-viable and, if it occurred on a wide scale, the embryo non-viable because a normal cytoskeleton is critical to cell function and embryo development (Barnett et al. 1997, Matsumoto et al. 1998, Wang et al. 2000). Indeed, because the cytoskeleton supports the cell plasma membrane and maintains intracellular organelle organisation (Boldogh et al. 1998, Valderrama et al. 1998), cytoskeleton disruption probably explains most of the freezing-induced changes in cell morphology and organelle distribution described previously for cryopreserved horse embryos (Ferreira et al. 1997).

In the current study, cell damage was predominantly an effect of freezing and thawing per se rather than of glycerol toxicity; this broadly supports the findings of Wilson et al. (1987) who reported consistent mitochondrial damage in embryos cryopreserved in $10 \%$ glycerol but only sporadic abnormalities in embryos exposed to glycerol without freezing. That other authors arrived at the contradictory conclusion that glycerol toxicity is the more significant fac- 

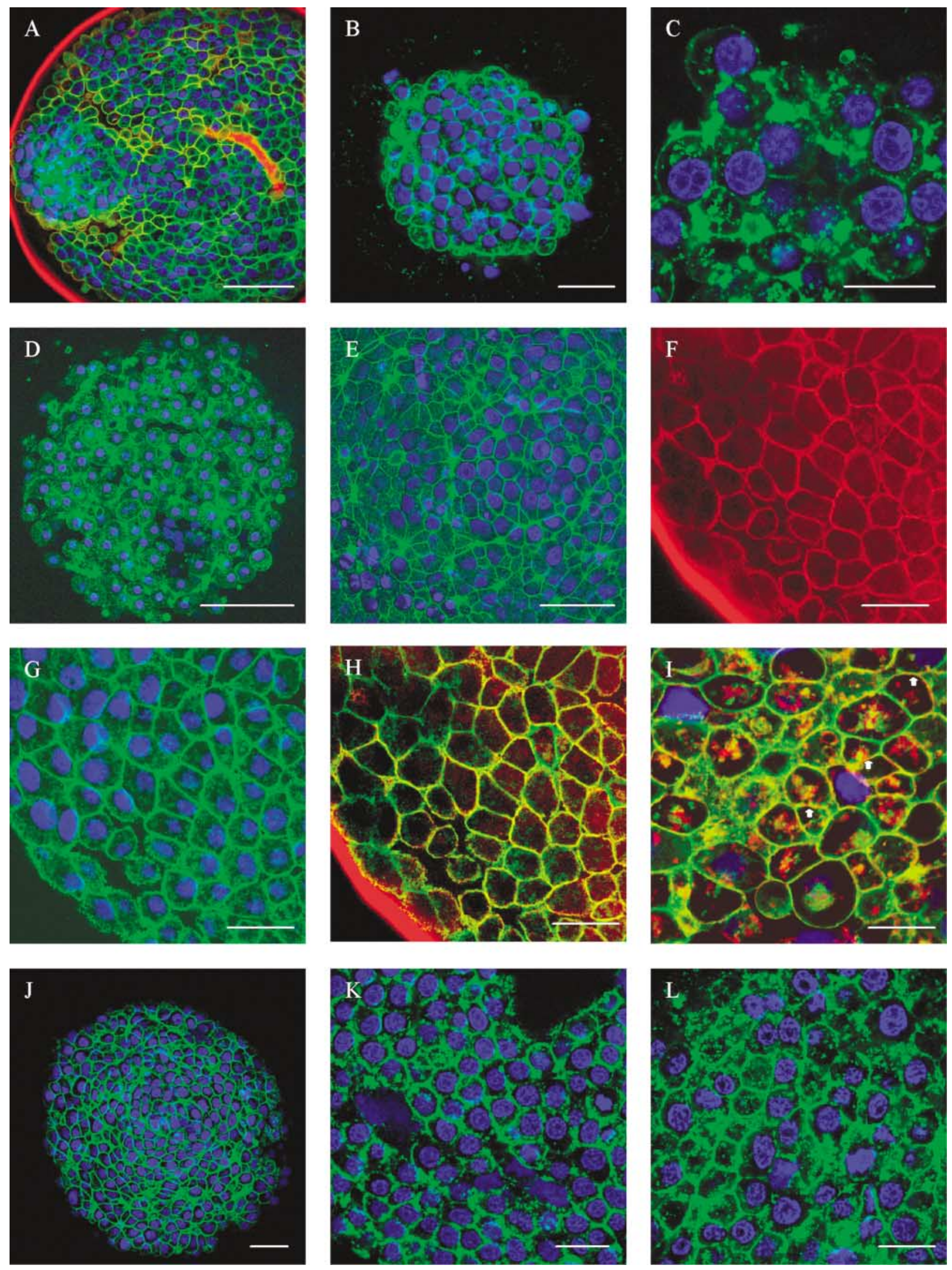
Table 2 Mean \pm S.E.M. embryo diameter prior to treatment, and cell number and percentage of dead cells after treatment with glycerol, with or without trypsin or cyto-B, and freezing and thawing.

\begin{tabular}{|c|c|c|c|c|}
\hline Treatment & Group (no. of embyros) & Diameter $(\mu \mathrm{m})$ & Total cell number & $\%$ dead cells \\
\hline \multirow[t]{2}{*}{ Non-treated controls } & $\leq 300 \mu \mathrm{m}(5)$ & $244 \pm 19.4$ & $648 \pm 226$ & $0.2 \pm 0.1$ \\
\hline & $>300 \mu \mathrm{m}(5)$ & $460 \pm 78.0$ & $2285 \pm 772$ & $0.1 \pm 0.0$ \\
\hline \multirow[t]{2}{*}{ Conventional freezing } & $\leq 300 \mu \mathrm{m}$ & $244 \pm 17.2$ & $731 \pm 129$ & $8.5 \pm 2.1^{\mathrm{a}}$ \\
\hline & $>300 \mu \mathrm{m}(7)$ & $445 \pm 31.7$ & $2161 \pm 701$ & $19.0 \pm 2.9^{b}$ \\
\hline \multirow[t]{2}{*}{ Trypsin pretreatment } & $\leq 300 \mu \mathrm{m}(4)$ & $235 \pm 29.9$ & $445 \pm 95$ & $5.4 \pm 0.7$ \\
\hline & $>300 \mu \mathrm{m}(4)$ & $565 \pm 134.2$ & $2861 \pm 1052$ & $13.8 \pm 4.9$ \\
\hline \multirow[t]{2}{*}{ Cyto-B pretreatment } & $\leq 300 \mu \mathrm{m}(4)$ & $225 \pm 18.9$ & $483 \pm 202$ & $8.1 \pm 2.3$ \\
\hline & $>300 \mu \mathrm{m}(7)$ & $553 \pm 82.7$ & $3292 \pm 935$ & $12.3 \pm 5.5$ \\
\hline \multirow[t]{2}{*}{ Cyto-B +6 -h post-thaw incubation } & $\leq 300 \mu \mathrm{m}(3)$ & $186.7 \pm 6.7$ & $290 \pm 40$ & $6.3 \pm 1.5$ \\
\hline & $>300 \mu \mathrm{m}(3)$ & $433 \pm 59.2$ & $757 \pm 108$ & $11.7 \pm 1.3$ \\
\hline
\end{tabular}

${ }^{a, b}$ Within a column, different superscripts denote values that different significantly within a treatment $(P<0.05)$

tor (Rieger et al. 1991, Bruyas et al. 1993, 1995) appears to be primarily a result of marked between-study differences in the duration of incubation post thaw and the indices of cell death employed. Bruyas and co-workers categorised cells with electron microscopically detectable nuclear pycnosis after 6-h incubation in vitro as dead $(22-54 \%$ of cells; Rieger et al. 1991, Bruyas et al. 1993, 1995, 2000); we counted cells with a permeable plasma membrane soon after glycerol removal as dead (5-19\% of cells). Since a shorter culture $(1 \mathrm{~h})$ resulted in lower rates of cells classified as dead via electron microscopy (Wilson et al. 1987, Bruyas et al. 1993), and improved culture conditions dramatically reduced pycnosis (to 2-3\%; Bruyas et al. 2000), it appears that the toxic effects of glycerol were exaggerated by the culture system used in earlier studies. Overall, it appears that glycerol may induce mild damage at the level of mitochondria that progresses to affect cell viability only if the embryo is forced to develop further in a suboptimal environment. Other factors likely to affect the apparent severity of glycerol toxicity include the equilibration procedure and the size/developmental stage of the embryo. In particular, relatively slow addition of glycerol (e.g. $4 \times 10$-min steps) is thought to increase the final intracellular glycerol concentration and thereby reduce osmotic cell damage (Bruyas et al. 2000); the fewer, shorter glycerol equilibration steps used in earlier studies may thus have exacerbated cell damage. With regard to embryo size, while most studies examined glycerol toxicity in relatively small day-6 embryos, we concentrated on day-7 expanded blastocysts more likely to sustain damage during freezing. This may have influenced the susceptibility to glycerol toxicity since Legrand et al. (2000) recently reported that blastocysts with a thick capsule suffer little cell death during equilibration in glycerol, possibly because the capsule completely blocks glycerol and fluid movements and thereby prevents cryoprotectant-induced osmotic cell damage. However, since these authors also report that a moderately thick capsule leads to the highest rates of cryoprotectant-induced cell death (they propose that in this situation water can exit but glycerol cannot enter), it must be assumed that trypsin treatment increases the permeability of the capsule to glycerol more dramatically than would be possible by a straightforward partial reduction in thickness.

The only pre-freezing treatment that noticeably affected embryo quality in the current study was cyto-B which, as expected, led to dispersal of actin from the cell cortex. Unexpectedly, the pattern of actin depolymerisation observed in cyto-B-treated horse embryos was very different from the complete disappearance of staining reported for similarly treated pig embryos (Dobrinsky et al. 2000). This suggests either that the cyto-B treatment used in the current study did not induce complete actin depolymerisation, or that depolymerisation takes different forms in these two species. Nevertheless, culturing cyto-B-treated embryos for $4 \mathrm{~h}$ in cyto-B-free medium allowed recovery

Figure 3 Photomicrographs to illustrate the actin cytoskeleton morphology of fresh and frozen-thawed equine embryos cryopreserved after different pre-freezing treatments. Embryos were stained with Alexa Fluor 488-phalloidin (green) to visualise the actin cytoskeleton, DAPI for the cell nuclei (blue) and WGA to label the lectin-reactive elements in the plasma membrane (red), and then examined using a multiphoton excitation microscope. Scale bars represent $100 \mu \mathrm{m}$ (A, D, E and J) and $50 \mu \mathrm{m}$ (B-C, F-I and K-L). (A to C) The actin cytoskeleton of non-frozen embryos treated with (A) glycerol, (B) glycerol and trypsin or (C) glycerol and cyto-B. Panel (A) has been additionally stained with WGA, and the surrounding red layer is the lectin-containing blastocyst capsule. ( $D$ and $E$ ) Cyto-B-treated embryos were incubated for an extra (D) $2 \mathrm{~h}$ or (E) $4 \mathrm{~h}$ in cyto-B-free medium; a 4-h incubation was sufficient for complete actin repolymerisation. (F to $\mathrm{G}$ ) Triple staining of actin (green), cell nuclei (blue) and WGA-reactive lectins in the plasma membrane and blastocyst capsule (red) of a control (non-frozen) embryo. Panels ( $F$ and G) respectively show staining with WGA or phalloidin separately; panel $(\mathrm{H})$ shows the superimposition of the two, and thereby demonstrates that WGA and phalloidin staining were colocalised at the cell borders. (I) Embryo frozen after trypsin pretreatment and stained with WGA and phalloidin. The white arrows show the WGA-labelled outline of the intact plasma membrane in areas where the actin cytoskeleton has been disrupted. (J) Grade I actin cytoskeleton in an embryo frozen and thawed after trypsin pretreatment. ( $\mathrm{K}$ and $\mathrm{L}$ ) Actin cytoskeleton of frozen-thawed embryos pretreated with cyto-B and either (K) fixed immediately after thawing and removal of glycerol or (L) following an extra 6-h incubation in OCM in an attempt to reverse the actin depolymerisation. 


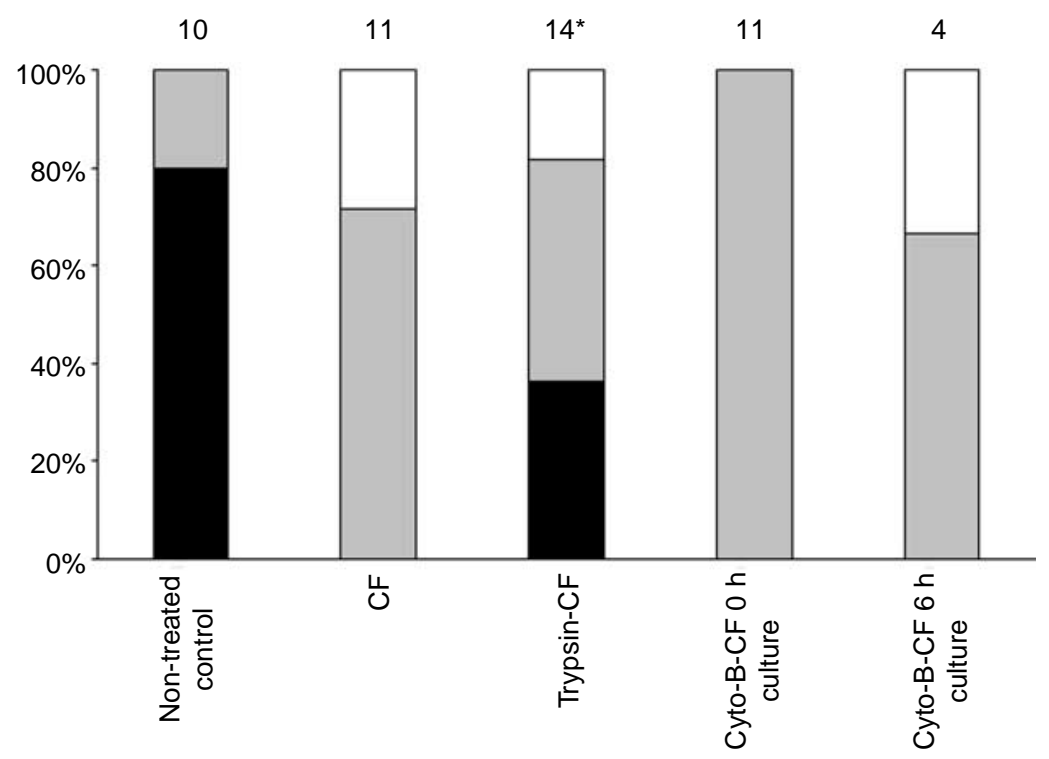

Figure 4 Actin cytoskeleton quality of horse embryos frozen in 10\% glycerol following different pre-freezing treatments $(\mathrm{CF}=\mathrm{conventional}$ slow freezing). Solid bars = grade I; grey bars = grade II; open bars = grade III. The number of embryos in each group is noted above each column. *Trypsin pretreatment significantly increased the likelihood of a grade I cytoskeleton post thaw $(P=0.02)$.

of a grade I cytoskeleton, thereby demonstrating that the depolymerisation was reversible.

Freezing and thawing disrupted the actin cytoskeleton and induced cell death in all treatment groups, but small embryos $(<300 \mu \mathrm{m})$ tended to suffer less damage. In fact, the effect of size only reached statistical significance in embryos frozen using the standard glycerol protocol, primarily because large embryos in this group tended to suffer more cell death than in others; this suggests that trypsin and cyto-B may preferentially protect larger embryos. In the case of trypsin, this supports the finding of Legrand et al. (1999) that partial capsule digestion reduces cell death during cryopreservation. In addition, because in the current study only embryos pretreated with trypsin maintained a grade I cytoskeleton post thaw, it appears that thinning the capsule prevents cytoskeleton disruption during freezing. However, trypsin treatment also resulted in a 'stickier', more difficult to handle capsule and, since the capsule is essential for conceptus survival in vivo (Stout et al. 2005), it is possible that the poor pregnancy rates recorded in recent studies with trypsin-treated frozen-thawed blastocysts (Legrand et al. 2002, Maclellan et al. 2002) were a result of loss of the 'sticky' capsule during ET. Cyto-B has been proposed to reduce cell damage during embryo freezing or manipulation by depolymerising actin filaments and thereby increasing the flexibility of cell plasma membranes (Huhtinen et al. 1995); this may be why cyto-B-treated embryos in the current study tended to be less likely to fracture during thawing. In the case of pig embryos, cyto-B treatment prior to vitrification reduced cytoskeleton disruption and improved survival of expanded blastocysts, but not morulae or early blastocysts (Dobrinsky et al. 2000). The results of the current study similarly suggest that any protective effects of cyto-B during the cryopreservation of horse embryos are preferential to large blastocysts. On the other hand, the effects of cyto-B on the cytoskeleton could not be reversed during a 6 -h post-thaw incubation, whereas in non-frozen embryos the cytoskeLeton repolymerised within $4 \mathrm{~h}$. The failure, or delay, of cytoskeleton regeneration post thaw could be because freezing critically damaged the cytoskeleton or its reassembly mechanism. In this respect, cytoskeleton regeneration is powered by mitochondria (Ahn et al. 2002), and mitochondrial damage during freezing (Wilson et al. 1987) might have delayed or prevented this process. Nevertheless, since Maclellan et al. (2002) were able to establish pregnancies with frozen-thawed cyto-B-treated horse embryos, cytoskeleton recovery must be possible after freezing and thawing and, as proposed for recovery from glycerol toxicity, it could be that any damage is more readily compensated in vivo than in vitro.

In conclusion, the current study used fluorescent stains to demonstrate that cryopreserving horse embryos leads to cytoskeleton disruption and cell death. Equilibration in glycerol, with or without cyto-B or trypsin, had no detectable lasting detrimental effects on cell architecture or viability. Trypsin pretreatment significantly improved the likelihood of an embryo maintaining an intact cytoskeleton during freezing, but further evidence that trypsin or cyto-B protected expanded blastocysts during cryopreservation was marginal. Moreover, questions remain about the suitability of these treatments because trypsin alters the physical characteristics of the blastocyst capsule, and cyto-B-induced actin depolymerisation is difficult to reverse after thawing. Nevertheless, cytoskeleton structure 
post thaw may be a valuable parameter for embryo quality and, as more fluorescent markers for intracellular structure and function become available, it is proposed that this approach will become an increasingly useful and sensitive adjunct to ET for evaluating the suitability of various freezing techniques.

\section{Acknowledgements}

The authors would like to thank all of the staff at the Research Centre for Horse Husbandry, Lelystad (The Netherlands) for their help with horse management during this study. We would also like to thank A M de Graaf and J A Valentijn of the Centre for Cell Imaging, Department of Biochemistry and Cell Biology (Utrecht University) for their assistance and helpful comments on fluorescent staining techniques and the use of the multiphoton laser scanning microscope. The authors declare that there is no conflict of interest that would prejudice the impartiality of this work.

\section{References}

Ahn HJ, Sohn IP, Kwon HC, Jo do H, Park YD \& Min CK 2002 Characteristics of the cell membrane fluidity, actin fibers, and mitochondrial dysfunctions of frozen-thawed two-cell mouse embryos. Molecular Reproduction and Development 61 466-476.

Barnett DK, Clayton MK, Kimura J \& Bavister BD 1997 Glucose and phosphate toxicity in hamster preimplantation embryos involves disruption of cellular organization, including distribution of active mitochondria. Molecular Reproduction and Development $\mathbf{4 8}$ 227-237.

Battut I, Colchen S, Fieni F, Tainturier D \& Bruyas JF 1997 Success rates when attempting to nonsurgically collect equine embryos at 144, 156 or 168 hours after ovulation. Equine Veterinary Journal Suppl 60-62.

Betteridge KJ, Eaglesome MD, Mitchell D, Flood PF \& Beriault R 1982 Development of horse embryos up to twenty two days after ovulation: observations on fresh specimens. Journal of Anatomy 135 191-209.

Boldogh I, Vojtov N, Karmon S \& Pon LA 1998 Interaction between mitochondria and the actin cytoskeleton in budding yeast requires two integral mitochondrial outer membrane proteins, Mmm1p and Mdm10p. Journal of Cell Biology 141 1371-1381.

Bruyas JF, Bézard J, Lagneaux D \& Palmer E 1993 Quantitative analysis of morphological modifications of day 6.5 horse embryos after cryopreservation: differential effects on inner cell mass and trophoblast cells. Journal of Reproduction and Fertility 99 15-23.

Bruyas JF, Battut I, Pol JM, Botrel C, Fieni F \& Tainturier D 1995 Quantitative analysis of morphological modifications of day 6.5 horse embryos after treatment with four cryoprotectants: differential effects on inner cell mass and trophoblast cells. Biology of Reproduction Monograph Series 1 329-339.

Bruyas JF, Sanson JP, Battut I, Fiéni F \& Tainturier D 2000 Comparison of the cryoprotectant properties of glycerol and ethylene glycol for early (day 6) equine embryo. Journal of Reproduction and Fertility 56 Suppl 549-560.

Carnevale EM, Squires EL \& McKinnon AO 1987 Comparison of Ham's F10 with $\mathrm{CO}_{2}$ or Hepes buffer for storage of equine embryos at $5 \mathrm{C}$ for $24 \mathrm{H}$. Journal of Animal Science 65 $1775-1781$.

Carney NJ, Squires EL, Cook VM, Seidel JGE \& Jasko DJ 1991 Comparison of pregnancy rates from transfer of fresh versus cooled, transported equine embryos. Theriogenology 36 23-32.

Czlonkowska M, Boyle MS \& Allen WR 1985 Deep freezing of horse embryos. Journal of Reproduction and Fertility 75 485-490.
Dobrinsky JR 1996 Cellular approach to cryopreservation of embryos. Theriogenology 45 17-26.

Dobrinsky JR, Pursel VG, Long CR \& Johnson LA 2000 Birth of piglets after transfer of embryos cryopreserved by cytoskeletal stabilization and vitrification. Biology of Reproduction 62 564-570.

Ferreira JCP, Meira C, Papa FO, Landin e Alvarenga FC, Alvarenga MA \& Buranti J 1997 Cryopreservation of equine embryos with glycerol plus sucrose and glycerol plus 1,2-propanediol. Equine Veterinary Journal 25 Suppl 88-93.

Flood PF, Betteridge KJ \& Diocee MS 1982 Transmission electron microscopy of horse embryos three to 16 days after ovulation. Journal of Reproduction and Fertility 32 Suppl 319-327.

Huhtinen M, Bredbacka P \& Kotilainen T 1995 Non-surgical transfer of DAPI-stained equine demi-embryos treated with cytochalasin B and nocodazole. Biology of Reproduction Monograph Series $\mathbf{1}$ 325-328.

Lascombes FA \& Pashen RL 2000 Results from embryo freezing and post ovulation breeding in a commercial embryo transfer programme. Proceedings of the 5th International Symposium on Equine Embryo Transfer, Saari, Finland. Havemeyer Foundation Monograph Series 3, pp 95-96.

Legrand E, Bencharif D, Battut I, Taintuier D \& Bruyas JF 1999 Horse embryo freezing: influence of thickness of the capsule. Proceedings of the 15th Scientific Meeting of the European Embryo Transfer Association, pp 184-185.

Legrand E, Krawiecki, JM, Tainturier D, Cornière P, Delajarraud H \& Bruyas JF 2000. Does the embryonic capsule impede the freezing of equine embryos? Proceeding of the 5th International Symposium on Equine Embryo Transfer, Saari, Finland. Havemeyer Foundation Monograph Series 3, pp 62-65

Legrand $E$, Bencharif $D$, Barrier-Battut $I$, Delajarraud $H$, Cornière $P$, Fiéni F, Tainturier D \& Bruyas JF 2002 Comparison of pregnancy rates for days $7-8$ equine embryos frozen in glycerol with or without previous enzymatic treatment of their capsule. Theriogenology $58721-723$.

Maclellan LJ, Carnevale EM, Coutinho da Silva MA, McCue PM, Seidel JGE \& Squires EL 2002 Cryopreservation of small and large equine embryos pre-treated with cytochalasin-B and/or trypsin. Theriogenology 58 717-720.

Matsumoto H, Shoji N, Umezu M \& Sato E 1998 Microtubule and microfilament dynamics in rat embryos during the two-cell block in vitro. Journal of Experimental Zoology 281 149-153.

McKinnon AO \& Squires EL 1988 Morphologic assessment of the equine embryo. Journal of American Veterinary Medicine Association 192 401-406.

McKinnon AO, Squires EL, Voss JL \& Cook VM 1998 Equine embryo transfer: a review. Compendium on Continuing Education for the Practicing Veterinarian $10343-355$.

Meadows SM, Lisa H \& Welsh C 1999 Factors affecting embryo recovery, embryo development and pregnancy rate in a commercial embryo transfer programme. In The First Meeting of the European Equine Gamete Group, Lopuszna, Poland. Havemeyer Foundation Monograph Series 1 pp 61-62 .

Meira C, Alvarenga MA, Papa FO, Oba E \& Landim e Alvarenga FC 1993 Cryopreservation of equine embryos using glycerol and 1,2propanediol as cryoportectant. Equine Veterinary Journal 15 Suppl 64-66.

Palmer E \& Jousset B 1975 Synchronization of oestrus in mares with a prostaglandin analogue and HCG. Journal of Reproduction and Fertility 23 Suppl 269-274.

Rieger D, Bruyas JF, Lagneaux D, Bézard J \& Palmer E 1991 The effect of cryopreservation on the metabolic activity of day 6.5 horse embryos. Journal of Reproduction and Fertility $4 \mathbf{4}$ Suppl 411-417.

Riera FL \& McDonough J 1993 Commercial embryo transfer in polo ponies in Argentina. Equine Veterinary Journal 15 Suppl 116-119.

Robinson SJ, Neal H \& Allen WR 2000 Modulation of oviductal transport in mares by local application of prostaglandin E2. Journal of Reproduction and Fertility 56 Suppl 587-592. 
Skidmore JA, Boyle MS \& Allen WR 1991 A comparison of two different methods of freezing horse embryos. Journal of Reproduction and Fertility $\mathbf{4 4}$ Suppl 714-716.

Slade NP, Takeda T, Squires EL, Elsden RP \& Seidel GEJ 1985 A new procedure for the cryopreservation of equine embryos. Theriogenology 24 45-58.

Squires EL, McCue PM \& Vanderwall D 1999 The current status of equine embryo transfer. Theriogenology 51 91-104.

Squires EL, Carnevale EM, McCue PM \& Bruemmer JE 2003 Embryo technologies in the horse. Theriogenology 59 151-170.

Stout TAE, Meadows SM \& Allen WR 2005 Stage-specific formation of the equine blastocyst capsule is instrumental to hatching and to embryonic survival in vivo. Animal Reproduction Science.

Valderrama F, Babia T, Ayala I, Kok JW, Renau-Piqueras J \& Egea G 1998 Actin microfilaments are essential for the cytological position and morphology of the golgi complex. European Journal of Cell Biology 76 9-17.
Vogelsang SG, Bondioli KR \& Massey JM 1985 Commercial application of equine embryo transfer. Equine Veterinary Journal 3 Suppl 89-91.

Wang WH, Abeydeera LR, Prather RS \& Day BN 2000 Actin filament distribution in blocked and developing pig embryos. Zygote $\mathbf{8}$ 353-358.

Wilson JM, Caceci T, Potter GD \& Kraemer DC 1987 Ultrastructure of cryopreserved horse embryos. Journal of Reproduction and Fertility 35 Suppl 405-417.

Received 13 December 2004

First decision 21 January 2005

Revised manuscript received 23 February 2005

Accepted 21 March 2005 